Fryderyk Zawadzki, Marta Wajda-Pokrontka, Tomasz Stącel, Maciej Urlik, Mirosław Nęcki, Remigiusz Antończyk, Magdalena Latos, Maria Królikowska, Damian Maruszak, Marcelina Łazaj, Małgorzata Kowacka, Alina Kliczka, Marian Zembala, Marek Ochman

Department of Cardiac, Vascular and Endovascular Surgery and Transplantology, Medical University of Silesia in Katowice,

Silesian Centre for Heart Diseases, Zabrze, Poland

\title{
Emphysema as a possible complication of infant respiratory distress syndrome leading to lung transplantation
}

\begin{abstract}
Infant respiratory distress syndrome (IRDS) develops among premature infants due to structural immaturity of the lungs and insufficient production of pulmonary surfactant. Nowadays, treatment takes place under conditions of intensive care and includes oxygen therapy, mechanical ventilation, exogenous supplementation of pulmonary surfactant and antenatal corticosteroid therapy. The treatment of IRDS, especially mechanical ventilation, may lead to complications which can contribute to developing a severe dysfunction of the respiratory system. Unavailability of pharmacological treatment of IRDS and development of pulmonary barotrauma due to mechanical ventilation in our patient led to the forming of severe pulmonary interstitial emphysema. In this case report, lung transplantation was performed as an only successful therapeutic option.
\end{abstract}

Key words: IRDS, pulmonary surfactant, pulmonary barotrauma, pulmonary interstitial emphysema, lung transplantation

Adv Respir Med. 2021; 89: 211-215

\section{Introduction}

Infant respiratory distress syndrome (IRDS), formerly known as hyaline membrane disease, is a common problem among preterm infants. Its incidence is inversely proportional to gestational age (GA). Extremely preterm infants (GA $\leq 28$ weeks) run the highest risk, nevertheless IRDS also occurs among late preterm and even term infants, however, the incidence is adequately lower. A report prepared by the Safe Labor Consortium reveals that IRDS was diagnosed in 10.5\% of infants born at the $34^{\text {th }}$ week of gestation (WG), $6 \%$ at $35 \mathrm{WG}, 2.8 \%$ at $36 \mathrm{WG}, 1 \%$ at $37 \mathrm{WG}$, and $0.3 \%$ at $\geq 38$ WG [1]. The disorder is caused by developmental insufficiency of pulmonary surfactant production and structural immaturity in the lungs. Surfactant scarcity leads to inability to maintain open alveoli during end expiration [2].

Antenatal corticosteroid (ACS) therapy and application of exogenous surfactant has lowered the mortality and morbidity associated with RDS $[3,4]$ but has not eliminated them. Complications due to therapeutic interventions such as supplemental oxygen, positive pressure ventilation, and the use of endotracheal tubes still exist and result in different forms of pulmonary air leaks, which can lead to the development of emphysema.

\section{Case presentation}

This case report describes a 38-year-old woman who underwent lung transplantation in 2016 due to extremely advanced emphysema. The beginning of the disease is difficult to determine due to the lack of medical records and inaccurate patient history.

According to our best knowledge, the woman was born as a preterm infant in the 8th month of pregnancy with diagnosis of hospital-acquired pneumonia and IRDS. She required mechanical ventilation, however, the exogenous surfactant

Address for correspondence: Fryderyk Zawadzki, Department of Cardiac, Vascular and Endovascular Surgery and Transplantology, Silesian Center for Heart Diseases in Zabrze, Faculty of Medical Sciences in Zabrze, Zabrze, Poland; e-mail: zawadzkifryderyk@gmail.com

DOI: 10.5603/ARM.a2020.0174 | Received: 12.06.2020 | Copyright (C) 2021 PTChP | ISSN 2451-4934 | e-ISSN $2543-6031$

This article is available in open access under Creative Common Attribution-Non-Commercial-No Derivatives 4.0 International (CC BY-NC-ND 4.0) license, allowing to download articles and share them with others as long as they credit the authors and the publisher, but without permission to change them in any way or use them commercially. 
as well as the antenatal corticosteroid therapy couldn't have been administrated because they were not available at that time. The lack of ACS therapy and employment of postnatal mechanical ventilation without surfactant application were the plausible reasons for major lung immaturity, respiratory impairment and finally, initiated pulmonary interstitial emphysema. At the age of 2 , due to recurring respiratory infections and worsening exercise capacity, the patient was diagnosed with asthma. Despite complying accuracy and available pharmacological therapy (inhaled corticosteroid and short-acting $B_{2}$-adrenergic-agonist), asthma was not sufficiently controlled. The girl has undergone several pneumonia and bronchitis until she was 10. Asthma treatment was terminated at the age of 11 due to lack of symptoms and achieved remission.

According to the patient medical history, there were no cases of severe emphysema in her family, she was not an active or passive smoker either. The patient had no environmental exposures and before the labor she had an office work.

In 2006, the woman became pregnant and from the very beginning complained of escalating dyspnea. After she went into a labor, a significant deterioration of the respiratory function occurred, and a quickly progressing emphysema was revealed in the chest X-ray examination - a cesarean section was conducted. Since delivery, she has been hospitalized for a few times due to significant deterioration of general condition with increasing exertion and rest dyspnea, every time being treated with antibiotics, steroids and bronchodilators. The bronchial obturation reversibility test was conducted with the following results: before bronchodilator-forced expiratory volume in 1 second $\left(\mathrm{FEV}_{1}\right)=18 \%$, forced expiratory volume in 1 second to forced vital capacity ratio $\left(\mathrm{FEV}_{1} / \mathrm{FVC}\right)=40 \%$ and after bronchodilator $-\mathrm{FEV}_{1}=23 \%, \mathrm{FEV}_{1} / \mathrm{FVC}=42 \%$.

In 2014, she was admitted to the Silesian Center for Heart Diseases for preliminary qualification to lung transplantation. Alpha 1-antitrypsin deficiency and connective tissue diseases were excepted. Echocardiography did not reveal any abnormalities and did not indicate the presence of pulmonary hypertension (right ventricle systolic pressure $=25 \mathrm{~mm} \mathrm{Hg}$, acceleration time $=$ $143 \mathrm{~ms}$, tricuspid annular plane systolic excursion $=21 \mathrm{~mm}$, left ventricle ejection fraction $=$ $55 \%)$. During the six-minute walk test (6MWT), the patient reached the distance of $356 \mathrm{~m}$ with 2 points in the Borg scale and $8 \%$ of desaturation during the test. After 11 months, a decision of the

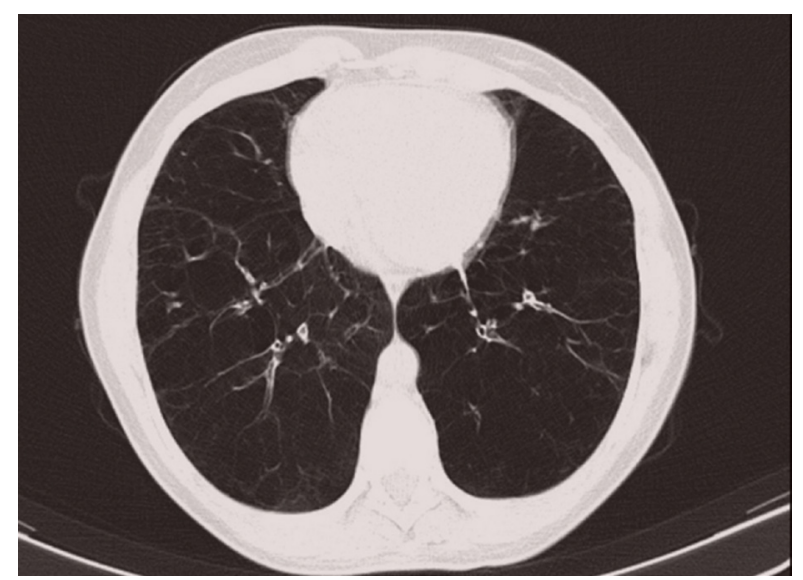

Figure 1. Results of computed tomography scan of the patient's chest from the qualification day for lung transplantation - multiple emphysematous bullae

patient's qualification for lung transplantation was made. The woman demonstrated exacerbation of lung dysfunction $\left(\mathrm{FEV}_{1}=21 \%, \mathrm{FEV}_{1} / \mathrm{FVC}=59 \%\right)$ and deterioration of general state. In computed tomography, multiple emphysematous bullae were observed (Figure 1). The 6MWT must have been stopped after 4 minutes - in that time the patient reached the distance of 189 meters with 5 points in the Borg scale, and desaturation from $97 \%$ to $91 \%$ was observed (after the test oxygen was required).

Nine months after qualification, the woman with an end-stage respiratory failure was admitted to the transplantology ward for lung transplantation due to the availability of a compatible donor. Uncomplicated, sequential double lung transplantation was performed. Immunosuppressive maintenance therapy including tacrolimus and prednisone was administered. One month after the surgery, the patient was admitted to the department due to the warning symptoms suggesting deterioration of lung function. The woman was diagnosed with mycotic infection with Aspergillus spp. as a result of immunosuppression therapy - voriconazole was administrated. During the next several months, the bronchiolitis obliterans syndrome occurred. Progression of bronchial stenosis was probably associated with past fungal infection. The patient underwent more than 50 balloon dilatations, more than 30 argon plasma coagulations, 2 laser therapy and 1 cryotherapy as bronchoscope interventions since lung transplantation procedure. Despite postoperative complications and multiple bronchial interventions, the patient's general state and respiratory function have prominently improved, which is reflected in her results. 2 years after transplantation, the woman achieved in spirometry $\mathrm{FEV}_{1}=63 \%$ and 


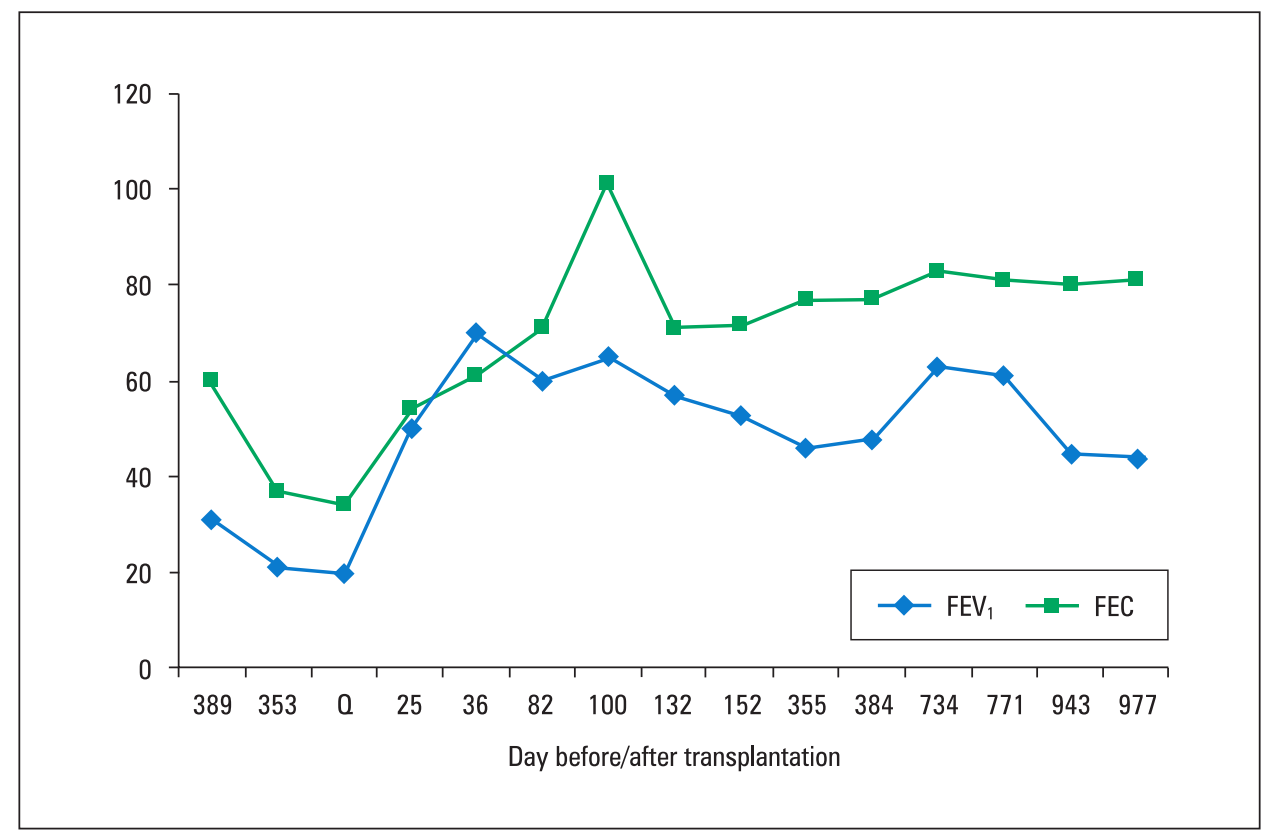

Figure 2. Detailed results of spirometry before and after transplantation (\% predicted of $F E V_{1}$ and FVC)

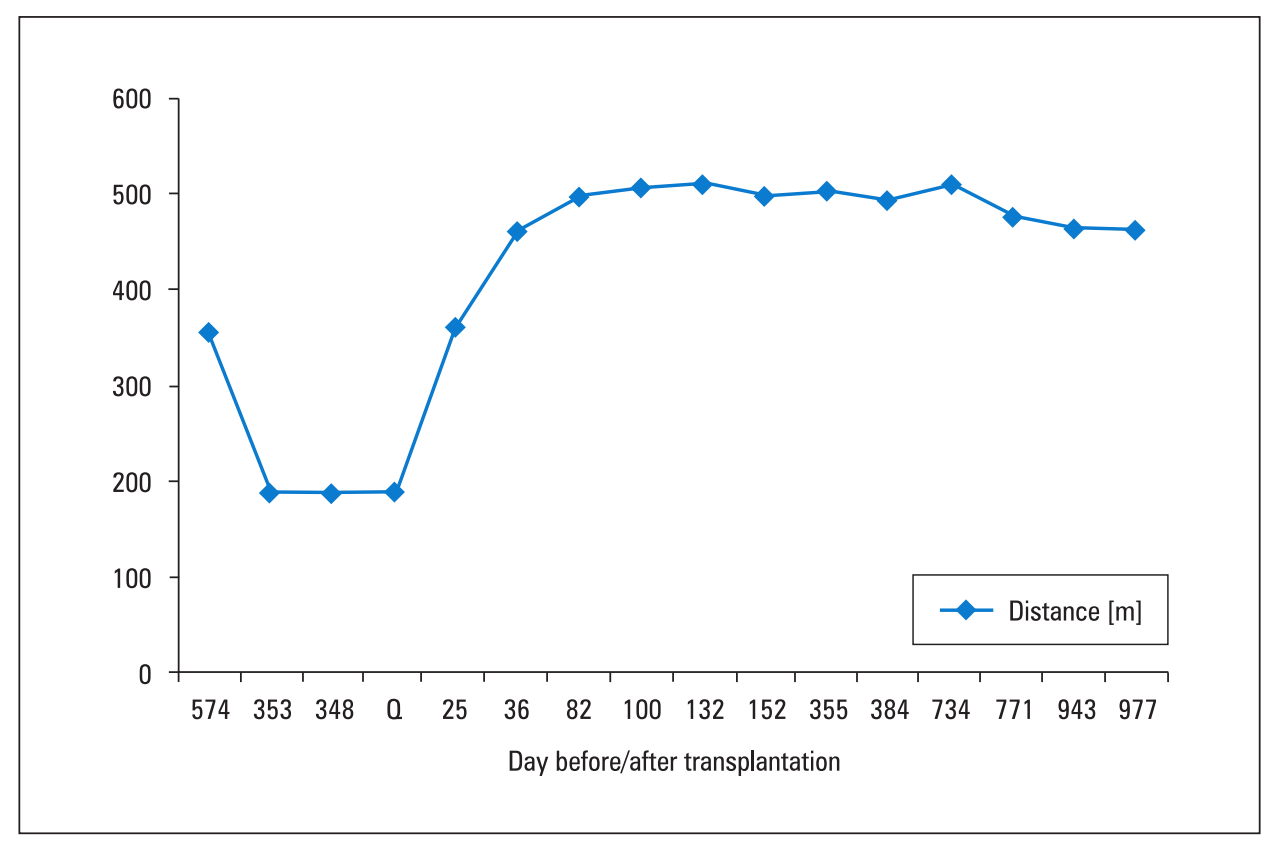

Figure 3. Detailed results of 6 minute walk test before and after transplantation

$\mathrm{FEV}_{1} / \mathrm{FVC}=79 \%$. In $6 \mathrm{MWT}$, she reached the distance of 510 meters with 3 points in the Borg scale and without desaturation. The results of spirometry and 6MWT following 5-year observation were presented in Figure 2 and Figure 3, respectively.

\section{Discussion}

The patient's condition that contributed to the decision about lung transplantation takes origin in a neonatal period and is a synthesis of several factors such as the absence of antenatal steroids therapy, lack of surfactant supplementation, pneumonia, invasive mechanical ventilation, severe asthma, recurring infections and labor.

Since the core of IRDS is lung immaturity, the best intervention would be to prevent delivery of premature infants. However, if preterm birth cannot be avoided, IRDS may be prevented, its severity decreased or its effects reduced by application 
of antenatal steroid therapy, exogenous surfactant supplementation and early administration of positive airway pressure. As a result of these measures, many extremely low birth weight infants do not exhibit the clinical features of RDS [5].

While mechanical ventilation is definitely lifesaving and has led to improvement in neonatal survival, it may cause severe and chronic lung damage. In this case, invasive mechanical ventilation was complicated by an air leak and resulted in pulmonary interstitial emphysema, which is characterized by trapping the gas from the alveoli inside the interstitial spaces of the lung and is diagnosed on the basis of chest radiography [6]. Clinical data suggest that this type of complication is associated with increased mortality and morbidity in preterm infants and can negatively affect long-term pulmonary and non-pulmonary outcomes [7]. The incidence of pulmonary interstitial emphysema in the randomized controlled trials evaluating prophylactic vs rescue surfactant therapy totaled $3 \%$ to $5 \%$ [8]. According to the one retrospective study, risk factors for developing pulmonary interstitial emphysema are higher maximum inspired oxygen concentration and higher mean airway pressures when compared with that in control subjects. Moreover, in infants weighing less than $1000 \mathrm{~g}$, these factors were associated with an increased risk of death [7].

Neonatal pneumonia may be both the reason for respiratory distress and an additional impairing factor in the preexisting one. Early-onset pneumonia is commonly presented by respiratory distress beginning at birth or soon after it, while the highest risk of late-onset pneumonia exists in the group of preterm infants who require assisted ventilation. Data from adults that are transposable to neonates show the four times higher risk of hospital-acquired pneumonia in intubated than in non-intubated patients [9].

Research efforts have been devoted to developing innovative ventilation strategies aiming to provide sufficient gas exchange along with decreased incidence of complications and damage [10]. According to the European Consensus Guidelines, CPAP should be preferentially started from birth in all infants at risk of RDS until their clinical status can be assessed. nCPAP is the preferred noninvasive alternative to endotracheal intubation and mechanical ventilation for very preterm infants (GA $\leq 32$ weeks) who are at risk of IRDS.

Volume-targeted ventilators provide a more consistent tidal volume, which results in lower lung injury rate than in pressure-limited venti- lation. Data have demonstrated that volume-targeted ventilation is associated with a lower risk of BPD and mortality than pressure-limited ventilation and is also reported to be superior to pressure-limited ventilation in the management of acute respiratory failure in neonates [11].

Antenatal administration of corticosteroids improves both lung mechanics and gas exchange through accelerating the development of type 1 and type 2 pneumocytes, which leads to structural and biochemical changes. A single course of antenatal corticosteroid therapy administered to women at risk of preterm delivery (PTD) reduce both prevalence and severity of respiratory distress syndrome as well as mortality in offspring, which was shown by Liggins and Howie in a landmark paper [12]. The outcome has been confirmed in over two dozen randomized trials [13].

A significant reduction in the incidence of IRDS among infants exposed to ACS therapy has been consonantly notified in randomized trials performed worldwide. In a 2017, a systematic review of randomized trials that compared antenatal corticosteroid therapy with placebo/no treatment among women at risk of preterm birth, ACS therapy resulted in a reduction in IRDS (RR $0.66,95 \%$ CI 0.56-0.77), reduction in moderate to severe disease (RR 0.59, 95\% CI 0.38-0.91) and reduction in need for mechanical ventilation (RR 0.68, 95\% CI 0.56-0.84) [13].

Exogenous surfactant replacement therapy is effective in reducing IRDS mortality and morbidity in preterm infants, which has been shown in several clinical trials conducted among preterm infants at the greatest risk of IRDS. In these trials, comparing surfactant therapy versus placebo, surfactant administration was associated with a lower prevalence and advancement of RDS, reduced mortality, and a decreased rate of associated complications such as pulmonary leak, including pulmonary interstitial emphysema [14].

Intubation and administration of surfactant is appropriate for the patients with persistent severe respiratory distress [required fraction of inspired oxygen to maintain oxygen saturation above $90 \%$ $\left(\mathrm{FiO}_{2}\right) \geq 0.40$ ] or who are apneic [15]. Surfactant therapy is most effective when administrated within the first 30 to 60 minutes of life and preceded by the placement of a pulse oximeter and clinical confirmation of correct endotracheal tube placement as well as balanced with appropriate time of nCPAP $[14,16]$.

What is remarkable, in the time when this patient was born, neither the antenatal corticosteroid therapy and surfactant replacement nor the 
noninvasive ventilation strategies were available, hence couldn't have been applied.

To conclude, premature infants with immature respiratory system demand comprehensive and specialized measures of protection and advanced therapy as early as possible, including antenatal age. Careful attention to many aspects of neonatal care such as antenatal corticosteroids therapy, delivery room resuscitation, ventilatory support and surfactant administration are needed to decrease pulmonary complications. Nevertheless, the results are not always as satisfying as supposed and may be not sufficient enough. By multicasual and long-lasting lung impairment, at some point of age, lung transplantation remains to be the only reasonable and lifesaving. therapeutic option for such patients.

\section{Conflict of interest}

None declared.

\section{References:}

1. Hibbard JU, Wilkins I, Sun L, et al. Respiratory morbidity in late preterm births. JAMA. 2010; 304(4): 419-425, doi: 10.1001/jama.2010.1015, indexed in Pubmed: 20664042.

2. Avery ME. Surfactant deficiency in hyaline membrane disease: the story of discovery. Am J Respir Crit Care Med. 2000; 161(4 Pt 1): 1074-1075, doi: 10.1164/ajrccm.161.4.16142, indexed in Pubmed: 10764292.

3. Fujiwara T, Maeta $\mathrm{H}$, Chida S, et al. Artificial surfactant therapy in hyaline-membrane disease. Lancet. 1980; 1(8159): 55-59, doi: 10.1016/s0140-6736(80)90489-4, indexed in Pubmed: 6101413.

4. Hintz SR, Poole WK, Wright LL, et al. Changes in mortality and morbidities among infants born at less than 25 weeks during the post-surfactant era. Arch Dis Child Fetal Neonatal Ed. 2005; 90(2): F128-F133, doi: 10.1136/adc.2003.046268, indexed in Pubmed: 15724036.
5. Finer N, Leone T. Oxygen saturation monitoring for the preterm infant: the evidence basis for current practice. Pediatr Res. 2009; 65(4): 375-380, doi: 10.1203/PDR.0b013e318199386a, indexed in Pubmed: 19127213.

6. Sivit CJ. Diagnostic imaging. In: Martin RJ, Fanaroff AA, Walsh MC (ed). Neonatal - erinatal medicine: diseases of the fetus and newborn, Philadelhia, Mosby. 2007: 713-731.

7. Verma RP, Chandra S, Niwas R, et al. Risk factors and clinical outcomes of pulmonary interstitial emphysema in extremely low birth weight infants. J Perinatol. 2006; 26(3): 197-200, doi: 10.1038/sj.jp.7211456, indexed in Pubmed: 16493434.

8. Morley CJ. Systematic review of prophylactic vs rescue surfactant. Arch Dis Child Fetal Neonatal Ed. 1997; 77(1): F70-F74, doi: 10.1136/fn.77.1.f70, indexed in Pubmed: 9279189.

9. Cross AS, Roup B. Role of respiratory assistance devices in endemic nosocomial pneumonia. Am J Med. 1981; 70(3): 681685, doi: 10.1016/0002-9343(81)90596-9, indexed in Pubmed: 6938128.

10. Donn SM, Sinha SK. Minimising ventilator induced lung injury in preterm infants. Arch Dis Child Fetal Neonatal Ed. 2006; 91(3): F226-F230, doi: 10.1136/adc.2005.082271, indexed in Pubmed: 16632652.

11. Klingenberg C, Wheeler KI, McCallion N, et al. Volume-targeted versus pressure-limited ventilation in neonates. Cochrane $\mathrm{Da}$ tabase Syst Rev. 2017; 10: CD003666, doi: 10.1002/14651858. CD003666.pub4, indexed in Pubmed: 29039883.

12. Avery CM, Liggins GC, Howie RN. A controlled trial of antepartum glucocorticoid treatment for prevention of the respiratory distress syndrome in premature infants. Pediatrics. 1972; 50(4): 515-525, indexed in Pubmed: $\underline{4561295}$.

13. Roberts D, Brown J, Medley N, et al. Antenatal corticosteroids for accelerating fetal lung maturation for women at risk of preterm birth. Cochrane Database Syst Rev. 2017; 3: CD004454, doi: 10.1002/14651858.CD004454.pub3, indexed in Pubmed: 28321847.

14. Suresh GK, Soll RF. Overview of surfactant replacement trials. J Perinatol. 2005; 25 Suppl 2: S40-S44, doi: 10.1038/ sj.jp.7211320, indexed in Pubmed: 15861172.

15. Committee on Fetus and Newborn, American Academy of Pediatrics. Respiratory support in preterm infants at birth. Pediatrics. 2014; 133(1): 171-174, doi: 10.1542/peds.2013-3442, indexed in Pubmed: $\underline{24379228}$.

16. Bahadue FL, Soll R. Early versus delayed selective surfactant treatment for neonatal respiratory distress syndrome. Cochrane Database Syst Rev. 2012; 11: CD001456, doi: 10.1002/14651858.CD001456.pub2, indexed in Pubmed: $\underline{23152207}$. 